\title{
INTRODUÇÃO AO DIREITO COMO CIÊNCIA SOCIAL 50 ANOS DEPOIS: EM HOMENAGEM AOS 90 ANOS DE CLÁUDIO SOUTO
}

\author{
Emmanuel Pedro Ribeiro*
}

\begin{abstract}
Resumo
O objeto de investigação foi o livro Introdução ao Direito como Ciência Social, de 1971. A hipótese foi a de que esse trabalho foi um divisor na obra do autor estudado. O livro contém as pesquisas anteriores e, ao mesmo tempo, projeta as investigações posteriores. Essa é uma razão, entre outras possíveis, que justifica nossa escolha. O objetivo geral consistiu em mostrar a que tradição sociológica Souto se alinha e, em que medida, o autor deu continuidade de modo original ao procurar determinar qualitativamente ou substantivamente o conteúdo de algo que pode ser chamado direito vivo ou simplesmente direito.
\end{abstract}

\section{Palavras-chave}

Introdução ao Direito como Ciência Social; Justiça; Direito; Moral; Equidade;

\section{INTRODUCTION TO LAW AS SOCIAL SCIENCE 50 YEARS LATER: IN HONOR OF CLÁUDIO SOUTO'S 90TH BIRTHDAY}

\begin{abstract}
The investigation's object was the book Introduction to Law as a Social Science, 1971. The hypothesis was that this work was a divider in the studied author's work. The book contains the previous researches and, at the same time, projects the subsequent investigations. This is the reason, among other possible ones, that justifies our choice. The general objective was to show what sociological tradition Souto is aligned with, and to what extent the author has continued in an original way by seeking to determine qualitatively or substantively the content of something that can be called living law or simply law.
\end{abstract}

Key-words

Introduction to Law as Social Science; Justice; Law; Morals; Equity;

\section{Introdução}

Este artigo tem algumas pretensões. A primeira delas procura salientar a originalidade do pensamento sociojurídico de um autor brasileiro e homenageá-lo nos seus 90 anos. Trata-se do primeiro a lecionar, no Brasil, de modo regular a disciplina Sociologia do Direito, em nível de graduação, em 1964, na Faculdade de Direito da Universidade Católica de Pernambuco (Cf. SOUTO e SOUTO, 1997 b, p. 107). A segunda tenta fazer uma análise o mais possível descritiva do pensamento do primeiro sociólogo do direito estudado pelo autor

\footnotetext{
* Mestre em Sociologia - UFPB Campus II; Mestre em Filosofia - UFPB Campus I; Bacharel em Direito Universidade Estadual da Paraíba - Campus I; CEP: 58.428-757; E-mail: emmanuelpedro@ hotmail.com.
} 
deste texto, ainda na graduação em Direito, em Pesquisa de Iniciação Científica, na Universidade Estadual da Paraíba. A terceira intenta mostrar a atualidade do livro Introdução ao Direito como Ciência Social meio século depois, ademais, a sua localização na trajetória acadêmica de Cláudio Souto.

O objeto de investigação é o livro Introdução ao Direito como Ciência Social, de 1971. A hipótese é a de que esse livro é um divisor na obra do autor estudado. O livro contém pesquisas anteriores e, ao mesmo tempo, projeta as investigações posteriores. Essa é uma razão, entre outras possíveis, que justifica a escolha dessa obra. O objetivo geral consiste em mostrar a que tradição sociológica Souto se alinha e, em que medida, o autor dá continuidade de modo original ao procurar determinar qualitativamente ou substantivamente o conteúdo de algo que pode ser chamado direito vivo ou simplesmente direito.

Os resultados preliminares dessa investigação, centrada em um único livro, revelam uma reconstrução da teoria jurídica ao determinar - através de pesquisa exploratória básica intitulada "O Sentimento e a Ideia de Justiça", realizada na Universidade de Colônia, na Alemanha, em 1965 -, as definições operacionais de justiça, direito, moral e equidade. O teste e a comprovação da hipótese construída por meio de pesquisa teórica básica ou de Sociologia Jurídica Básica apontam as condições de possibilidade a posteriori da conexão entre uma Teoria Sociológica Geral do Direito com uma Sociologia do Direito Aplicada.

Portanto, o que o autor denomina de nova Teoria Geral do Direito implica a reformulação das relações entre o que designa de saberes jurídicos fundamentais como: Lógica Jurídica ou Dogmática Jurídica, Sociologia do Direito e Filosofia Jurídica. Essa atitude implica na formulação de uma Teoria Geral Científico-Empírica do Direito com repercussões nos temas clássicos que compõem a Teoria Geral do Direito. Finalmente, salienta-se que o autor não faz distinção entre Sociologia do Direito e Sociologia Jurídica, são tidas como sinônimas, não há que falar-se, por um lado, em formulação própria de sociólogos e, por outro lado, em construção exclusiva de juristas. Pois para Souto, "não é isso evidentemente o relevante, mas apenas que as indagações sejam realmente científicas" (SOUTO e SOUTO, 1997 b, p. 38).

\section{I - Para situar o livro Introdução ao Direito como Ciência Social}


Esse livro data de 1971, contém um prefácio e oito capítulos. O prefácio oferece as razões e as grandes questões abordadas no livro. Verifica-se, de início, o deslocamento produzido no campo da Sociologia do Direito e do que denomina de saberes jurídicos fundamentais. Trata-se de uma Introdução a uma leitura interna do Direito. Souto não parte da existência do Direito como uma dimensão institucional da sociedade, que possui uma lógica autônoma de funcionamento e sobre o qual se realiza uma leitura sociológica ou externa das "causas" do seu surgimento e dos efeitos de sua criação, interpretação e aplicação. Para Souto, o critério de "legitimidade" do Direito não é o procedimento legalmente organizado, mas o conteúdo social do jurídico investigado através de métodos e técnicas de pesquisa empírica, baseada na observação controlada dos fatos (Cf. SOUTO, 1992: p. 38-39). Por isso se trata de um fazer sociológico para além do usual acadêmico.

Para Souto, a Sociologia do Direito é um ramo do conhecimento recente e ainda por fazer-se. Como certifica o que diz? Oferece duas razões para isso: a primeira, pela escassa bibliografia mundial sobre o tema, a segunda, pela ausência de definições precisas sobre os conceitos com que opera (Cf. SOUTO, 1971, p. XIII; 1978, p. 71; SOUTO e SOUTO, 1997 b, p. 45). A Ciência do Direito é uma Ciência Social que depende da Sociologia Geral e das demais Ciências Humanas para o seu desenvolvimento. Isso não implica a substituição, nem, tampouco, a negação do que o autor denomina de saberes tradicionais como os estudos lógico-jurídicos e filosófico-jurídicos. O deslocamento operado por ele e o caminho próprio que construiu se mostram claros ao afirmar:

Além da biblioteca jurídica - por muito tempo considerada o único laboratório da ciência do direito -, e além dos casos forenses, há todo um novo mundo jurídico por explorar - e esse mundo é o mundo da realidade social do direito, território vasto e intricado, porém riquíssimo (SOUTO, 1971, p. XIII-XIV).

Prossegue o autor:

Significa tão só que, já se havendo estudado tanto o que os juízes, ou legisladores, ou administradores decidem como justo - sem ter-se contudo, chegado a saber o que é justiça -, e sendo esta, ao que tudo indica, um fenômeno psíquico-social geral, é pelo menos [...] também proveitoso, estuda-la tal como se oferece à investigação no ambiente geral de sua vida, ambiente em que vivem igualmente juízes, legisladores e administradores: a sociedade (SOUTO, 1971, p. XIV).

Dessa forma:

A investigação sobre o sentimento e a ideia de justiça, em que se procura apreender a natureza do que se chamou o 'direito vivo' ou o direito tal como se dá na sociedade, não se pode limitar, de fato, à pesquisa do que sentem e pensam juízes, advogados, estudantes e professores de direito. Esses últimos - entre os quais se 
inclui o autor - constituem um mundo um tanto à parte, nem sempre com a percepção suficientemente clara do direito que, vivo, flui na sociedade, em interação com ela (SOUTO, 1971, p. XIV).

Consideramos esse trabalho um divisor na obra acadêmica de Souto, não obstante a dificuldade que implica uma tal afirmação. Além de ser o resultado de uma década de reflexão sobre a matéria, mostra-se esclarecedor sobre o percurso intelectual do autor. Por um lado, percebe-se como teses e pesquisas anteriores retornam como tópicos e subtópicos de capítulos do livro. Como exemplos, podemos citar: 1) tese de doutorado, de 1956, Da inexistência científico-conceitual do Direito Comparado: conceituação do indagar comparativo mais específico da Ciência do Direito; 2) Da Irrealidade jurídico-definitiva do Direito Natural: nova visualização do fenômeno jusnaturalista, vol. I de 1958, vol. II de 1960; 3) Introdução crítica ao Direito Internacional Privado, de 1964; 4) a pesquisa "O Sentimento e a Ideia de Justiça" realizada na Alemanha, na Universidade de Colônia, com a colaboração de Solange Souto, em 1965; 5) Fundamentos da Sociologia Jurídica, de 1968. Todos esses trabalhos parecem desembocar na elaboração de Introdução ao Direito como Ciência Social, de 1971. Por outro lado, contudo, esse livro parece conter as teses e pesquisas que vieram depois dele, a exemplo de: 1) Teoria Sociológica Geral, de 1974; 2) Teoria Sociológica do Direito e Prática Forense, de 1978; 3) Sociologia do Direito, de 1981, em coautoria com a professora Solange Souto; 4) A Explicação Sociológica: uma Introdução à Sociologia, em coautoria com a professora Solange Souto, de 1985; 5) O que é pensar Sociologicamente, de 1987; 6) Ciência e Ética no Direito: uma alternativa de Modernidade, de 1992; 7) Tempo do Direito Alternativo: Uma Fundamentação Substantiva, de 1997. A seguir, veremos, passo à passo, a busca de uma delimitação mais possível precisa do Direito como fato social como condição a posteriori de uma nova Teoria Geral do Direito (Cf. SOUTO, 1971, p. 146).

\section{II - Uma caracterização geral e ainda inespecífica do jurídico como fenômeno social}

O ponto de partida e, ao mesmo tempo, de chegada, tudo indica, radica no estabelecimento do processo social primário caracterizado pela ação recíproca ou sociointerativa de pelo menos dois compostos SIV, sendo $S=$ sentimento, I=ideia e V=volição. Cada indivíduo em sociedade é essencialmente um composto SIV e nos processos sociointerativos comunicam sentimentos, ideias e vontades. Desse modo, qualquer ação social implica uma pauta de conduta ou norma de ação que, em essência, se compõe de sentimento e de ideia do que deve ser. De modo que uma pauta de conduta ou norma de ação é produto da 
interação social, anulável ou modificável por interação. É desse processo social primário que derivam os processos sociais secundários que podem ser reduzidos ao controle social, à socialização e ao grupo social como modalidades do processo interativo. Assim, todos os conceitos da Sociologia podem ser explicados a partir da redução sociológica ao processo social primário. Para Souto, as normas sociais, inclusive as jurídicas, constituem a essência da vida social e toda a vida social pode ser explicada pelo estudo das normas de regulamentação sociais (Cf. SOUTO, 1971, p. 1-4; 1974, p. 13-30; SOUTO e SOUTO, 1985, p. 67-79).

Nesse sentido, o fenômeno jurídico, como qualquer fenômeno social, pode ser visto como norma e como conduta. Todavia, o que há de específico no fenômeno jurídico que o distingue dos outros fenômenos normativos igualmente sociais? Dado que todos os fenômenos normativos são imposições de conhecimentos, como se caracteriza uma regra de conduta social? Uma regra de conduta social equivale à União de um Imperativo com um Conhecimento determinado implicando em uma Norma imperativa que se refere a uma conduta social e a qualifica ou por ela é qualificada quando é criada pela própria conduta social. Temos, então, que a conduta pode ser normada, quando qualifica uma conduta. Pode ser também normante, quando inovadora e criadora de uma norma social. Para Souto, esse é o cerne da vida social e o fenômeno jurídico constitui um fenômeno de conduta social específico. A descrição feita acima pode ser simbolicamente formulada, tal como o faz nosso autor por meio de notação. Vejamos como o faz: $\mathrm{R}=$ Regra de conduta social, $\mathrm{I}=$ Imperativo, $\mathrm{C}=\mathrm{um}$ conhecimento determinado (indicativo), $\mathrm{N}=$ Norma imperativa e $\mathrm{S}=$ Conduta social (normada e normante).

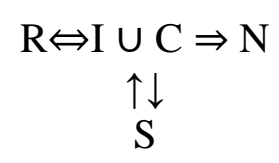

Fonte: Introdução ao Direito como Ciência Social. Rio de Janeiro: Tempo Brasileiro, 1971, p. 6.

A partir do esquema acima descrito, Souto sugere que uma Regra de conduta (R) é equivalente à União (U) de um Imperativo (I) com um Conhecimento determinado ( $\mathrm{C}=$ indicativo). A União de um Imperativo com um Indicativo ou conhecimento determinado, implica em uma Norma imperativa $(\mathrm{N})$. Essa Norma imperativa $(\mathrm{N})$ quando qualifica uma conduta (S) é chamada de conduta normada. Mas, essa Norma imperativa (N) quando criada por uma conduta (S) é designada de normante. Esse é o esquema da Regra de conduta social 
(Cf. SOUTO, 1971, p. 6; 1974, p. 80-95; SOUTO e SOUTO, 1985, p. 229-236; 1997b, p. 35). Demonstra-se aqui uma preocupação intensa em esboçar, de modo rigoroso, os fenômenos de regulamentação social, principalmente o jurídico porque considerado o mais social dos fenômenos de normação social. Para Souto, se o jurídico é tão essencial para a determinação da vida social, seria de esperar que se conferisse o máximo de importância aos estudos de Sociologia Jurídica, o que lhe parece não corresponder. Situação, no mínimo, paradoxal, dado que as regras jurídicas são reconhecidas, tradicionalmente, como mínimo pacificador indispensável, possuidoras de maior aceitação e de cumprimento mais gerais do que as outras normas de controle social, possuem um índice de socialização mais elevado, sempre se referem a relações humanas e podem ser impostas pela força pela via judiciária (Cf. SOUTO, 1971, p. 7; 1974, p. 110-111; SOUTO e SOUTO, 1985, p. 233).

\section{III - A Sociologia do Direito e as suas linhas mais gerais: uma abordagem específica}

A Sociologia do Direito é o conhecimento que enfatiza a sua indagação no fenômeno jurídico inserido, sempre, na dinâmica da realidade social total. A natureza fortemente específica do fenômeno social jurídico é que se trata de um fenômeno de dever ser, um fenômeno indicativo-imperativo sui generis. Por isso ela tende a uma metodologia relativamente específica e a constituir-se em uma Ciência Social Particular com tendência a autonomia (Cf. SOUTO, 1971, p. 12; SOUTO e SOUTO, 1997b, p. 35).

Sua tarefa fundamental é definir o direito como fato social, do modo mais preciso possível. Todas as outras tarefas possíveis pressupõem a delimitação do campo social do jurídico. Para que possa operar racionalmente precisa saber com um mínimo de precisão o que é o direito, a partir de uma observação da realidade social total. Da tarefa fundamental dependem as relações que possam estabelecer entre justiça e direito, direito e outras formas de regulamentação social, direito e força, direito e formas de coercibilidade (Cf. SOUTO, 1971, p. 13-15; 1974, p. 122-123; SOUTO e SOUTO, 1997 b, p. 39).

Desse modo, esse livro trata de uma Teoria Sociológica Geral sobre o jurídico, essa tem como centro as definições operacionais da justiça, do direito, da moral e da equidade, suas consequências mais imediatas, e suas correlações funcionais entre o direito e a realidade social total. Por referir-se aos Fundamentos da Sociologia Jurídica, de suas tarefas mais 
gerais, trata-se de uma investigação de Sociologia Jurídica Geral (Cf. SOUTO, 1971, p. 17; 1992, p. 39; SOUTO e SOUTO, 1997b, p. 36-39).

Parece tratar-se de uma Teoria Sociológica Básica do Direito que fornece subsídios para uma Sociologia Jurídica Aplicada. O estudo dos fundamentos da Sociologia Jurídica ou de uma Teoria Sociológica Geral sobre o jurídico fornece os elementos necessários para as tarefas gerais da sociologia do direito que dependem de uma pesquisa de campo básica sobre o que o direito é substantivamente. Nesse sentido, a Sociologia Jurídica ou Sociologia do Direito (Cf. SOUTO e SOUTO, 1997 b, p. 38) indaga a realidade social total em função do Direito, estudando as relações recíprocas existentes entre tal realidade social total e o fenômeno jurídico (Cf. SOUTO, 1971, p. 17; 1974, p. 122; SOUTO e SOUTO, 1997b, p. 39$40)$.

Rigorosamente, haveria três saberes jurídicos fundamentais: a Lógica do Direito, dedicada à análise do chamado "direito positivo" e correspondente ao que se tem chamado a ciência do direito dos juristas ou dogmática jurídica; a Sociologia do Direito, saber jurídico em sua infância e objeto de investigação desse livro; e a Filosofia do Direito, dedicada ao aprofundamento dos problemas jurídicos. Para Souto, esses três saberes básicos constituem ou devem constituir uma unidade, devem realizar um trabalho cooperativo para a formulação de uma teoria jurídica. Assim, pode-se dizer que o direito é um fenômeno social que se reveste de variadas formas de imposição (lei, costume, doutrina, decretos, regulamentos, contratos, decisão judicial, jurisprudência) e cujo conhecimento é passível de aprofundamento filosófico (Cf. SOUTO, 1971, p. 18; 1978, p. 13-25; 1992, p. 9-13; 1997 a, 16-24; SOUTO e SOUTO, 1997 b, p. 40-43, 210, 234).

Sociologia Jurídica ou Ciência Social do Direito ou em futuro próximo parecerá preferível usar a expressão Ciência do Direito. A Ciência Social do Direito não tem como objeto de estudo os sistemas particulares considerados singularmente para cada povo em uma época determinada. O jurista é salvo de posição pouco científica e servil face à Filosofia do Direito, sendo elevado à dignidade de cientista social, quando empregar e adaptar ao campo sociológico jurídico a empírica e ampla indução sociológica, tentando-se atingir, com validez transcultural, conceituação científica do direito (Cf. SOUTO, 1971, p. 20-21; 1974, p. 133136; 1978, p. 82-83; SOUTO e SOUTO, 1985, p. 243). 
O que se pretende é fazer a Sociologia Jurídica avançar sobre o território tradicionalmente considerado de exclusiva indagação filosófica, fazê-la conquistar novas regiões para o conhecimento científico-empírico, ao atingir conceituação científica do jurídico. Já não parecem subsistir como exclusivamente filosóficas, aquelas três indagações clássicas que se atribuíam à Filosofia do Direito, quais sejam as relativas à definição do jurídico em geral, ao direito que deverá ser ou deontologia jurídica e a que se denominou de fenomenológica. A Teoria Geral Científico-Empírica do Direito deverá anteceder à indagação filosófica do jurídico, pois lhe fornecerá os dados a partir dos quais a reflexão filosófica sobre o Direito incidirá. Uma ciência social empírica do direito pode concluir por critério científicoempírico transculturalmente válido do jurídico, quando tomar por base os dados fornecidos pela ciência etnológica e partir da observação empírica da realidade social, comparando esses dados com outros obtidos da observação de sociedades ditas civilizadas (Cf. SOUTO, 1971, p. 24-25; 1974, p. 133-134; 1978, p. 83; SOUTO e SOUTO, 1985, p. 243; 1997 b, p. 215216).

\section{IV - Os momentos da Sociologia Jurídica: despertar e desenvolvimento}

Importante observar que a história da Sociologia do Direito tem dois momentos fundamentais: um com ênfase na hostilidade e outro caracterizado pelo abandono, da parte de sociólogos e de juristas. Sociólogos a hostilizaram dado o desdém do cientificismo sociológico para com as normas e valores como objeto de investigação. Juristas a hostilizaram sob a suspeita de que esse ramo do saber desconsiderava o conhecimento do aspecto normativo e valorativo do Direito (Cf. SOUTO, 1971, p. 31-32; 1974, p. 111; 1978, p. 14; SOUTO e SOUTO, 1997 b, p. 65-66)

Nota-se atualmente uma espécie de abandono relativo. Do lado dos juristas, a ênfase no positivismo estatista sobretudo com Hans Kelsen (1881-1973) e que pretende uma ligação dogmaticamente necessária e enfática entre direito e Estado, como se inexistisse direito sem Estado (Cf. SOUTO, 1971, p. 33; 1974, p. 111; 1978, p. 15; SOUTO e SOUTO, 1997 b, p. 66). Esse momento tem sido dominado sobretudo por juristas-sociólogos, constituído quase exclusivamente por lógicos das técnicas coercíveis do direito. Não se trata de sociólogos em sentido próprio, nunca o foram, porém, caracterizam-se principalmente pelo conhecimento das técnicas do direito e, só de modo derivado, mostram-se interessadamente sociólogos. Por que? Dir-se-ia que são estranhamente sociólogos, porque fazem um uso meramente 
instrumental da Sociologia. Utilizam a Sociologia de modo subordinado, fazem uso dos seus dados em função das técnicas coercíveis do direito, mas não em seus métodos e técnicas de pesquisa (Cf. SOUTO, 1971, p. 35; SOUTO e SOUTO, 1997 b, p. 66).

Todavia, a Sociologia Jurídica como Ciência Social do Direito que é, constituiu-se como conhecimento despreconcebido e científico (Cf. SOUTO e SOUTO, 1985, p. 42-44; 1987, p. 7 e 11) foi obra de poucos teóricos do social que ousaram romper a barreira da hostilidade e do abandono, que perceberam a importância do direito, dentre as formas de regulamentação social, para a explicação da vida social total (Cf. SOUTO, 1971, p. 35; SOUTO e SOUTO, 1997 b, p. 66). A atitude de Souto no momento em que exerce a função de sociólogo, como homem de ciência e homem da dúvida, assume uma postura crítica e antidogmática. Por esse viés, pôs em destaque autores clássicos e contemporâneos, assinalando as contribuições de cada um e, simultaneamente, as insuficiências das suas definições do Direito. O seu percurso e a escolha que fez dos autores para com eles debater parece muito singular.

Percebe-se que a postura de Souto se assemelha à de Sócrates, personagem principal dos diálogos de Platão, pelo menos, daqueles chamados de "socráticos" ou da "fase socrática". A suposição é a de que esses diálogos espelharam a prática filosófica do mestre de Platão. Sócrates indagava os seus discípulos, concidadãos, adversários teóricos e políticos com a pergunta desconcertante: “O que é?" O que buscava Sócrates era a definição, o conceito das coisas, geralmente de uma virtude ou qualidade moral. Por exemplo, o diálogo Laques aborda a coragem como questão central. No diálogo Ménon a discussão é pautada pelo tema da virtude. No diálogo República a questão da justiça é o seu coração. Assim, temos: $\mathrm{O}$ que é coragem? O que é virtude? O que é justiça? Estas perguntas embaraçavam os seus interlocutores porque não conseguiam definir os conceitos de coragem, de virtude e de justiça (Cf. MARCONDES, 2008, p. 46-56). O limite dos interlocutores de Sócrates era a insuficiência das suas definiçõoes conceituais de coragem, de virtude e de justiça, para ficarmos nesses exemplos. Ficavam presos ao campo da mera opinião e não atingiam o conhecimento verdadeiro capaz de conferir unidade e universalidade ao conceito buscado.

Souto traça um quadro histórico da Sociologia do Direito. Na França, aborda o pensamento de Émile Durkheim (1858-1917), na Alemanha dialoga com Max Weber (18641920) e com Eugen Ehrlich (1862-1922), no Brasil, o seu autor é Pontes de Miranda (1892- 
1979). Ao tratar da Sociologia Jurídica nos Estados Unidos põe em relevo Underhill Moore (1879-1949), Roscoe Pound (1870-1964), Ralph Linton (1893-1953), Adamson Hoebel (1906-1993). No quadro da Sociologia do Direito na Escandinávia, aponta como o realismo da Escola de Upsala, fundada por Axel Hägerstrom (1868-1939), conta com nomes como Anders Vilhelm Lundstedt (1882-1955), Karl Olivercrona (1897-1980) e Alf Ross (18991979). Contudo, ainda considera Theodor Geiger como realista, embora de nacionalidade alemã, viveu na Dinamarca e pode ser tido como membro daquela Escola. Para Souto, esses autores prepararam o advento da Sociologia Jurídica na Escandinávia. No entanto, é digno de nota a referência de que a Sociologia do Direito escandinava se firmou, sobretudo, na área das pesquisas empíricas de atitude com respeito ao jurídico, abrindo-se a uma interface com a psicologia social. Trata da Escola psicológico-jurídica de Leon Petrazhitsky (1867-1931), um sociólogo russo-polonês, que teve grandes nomes como seus seguidores, a exemplo de Pitirim Sorokin (1889-1968), Nicholas Timashef (1886-1970) e Georges Gurvitch (1894-1965). Souto analisa o pensamento do sociólogo estadunidense Thomas Cowan, salienta as afinidades com o seu pensamento e aponta que ele parece se livrar do chamado resíduo cientificista no trato com normas e valores. Finalmente, encerra com os quatro anos mais recentes da Sociologia Jurídica, referindo-se às pesquisas desenvolvidas na Alemanha por Manfred Rehbinder (1935- ), na França por Jean Carbonier (1908-2003), na Itália por Renato Treves (1907-1992), nos Estados Unidos por Rita James Simon (1931-2013) e Edwin M. Schur (1930- ). Por último, aponta o significado e a atualidade da pesquisa exploratória "O Sentimento e a Ideia de Justiça", realizada na Alemanha por brasileiros em 1965, um ensaio de verificação empírica de uma teoria da justiça que busca alcançar a refinada síntese "pesquisa empírica teórica" que, a rigor, não se desenvolveu nem na Sociologia Jurídica da Europa, nem naquela dos Estados Unidos. A europeia com índice maior de teoria e a estadunidense com índice mais elevado de pesquisa empírica (Cf. SOUTO, 1971, p. 31-81; para um panorama mais atualizado vide, SOUTO e SOUTO, 1997 b, p. 65-102)

Como referido, o diálogo com todos os autores, clássicos e contemporâneos, da Sociologia Jurídica foi frutífero e mostrou os desenvolvimentos da pesquisa sociojurídica mundial entre 1966 e 1970. Souto apresenta as contribuições dos clássicos da Sociologia do Direito para o desenvolvimento da disciplina, verifica-se a presença de alguns deles na elaboração do seu pensamento, como acontece com os autores contemporâneos. São apontados as aproximações e os afastamentos com cada autor que mereceu uma referência 
nessa trajetória que vai do despertar ao desenvolvimento da Sociologia do Direito. Todavia, a questão que torna o diálogo e o debate mais interessantes é a que diz respeito às insuficiências de todas as definições do direito como fenômeno de normação social. Nenhum dos autores citados no parágrafo anterior conseguiu, de acordo com a perspectiva do nosso autor, dizer efetivamente o que o Direito substantivamente é. E essa é a tarefa por excelência, como Souto postula, de uma Teoria Geral Sociológica do Direito (Cf. SOUTO, 1978, p. 13)

Trata-se, tudo indica, de uma investigação sobre os Fundamentos da Sociologia do Direito ou de uma Sociologia Jurídica Básica (Cf. SOUTO e SOUTO, 1997 b, p. 39), mais especificamente, daquelas questões que eram exclusivas da Filosofia Jurídica. Souto aponta que a redução teorética-gnosiológica sobre o Direito ao campo da Filosofia redundou no que ele denominou de filosofismo tradicional (Cf. SOUTO, 1971, p. 20). Qual é, então, a sua questão? É a de que a Ciência Social do Direito começa a avançar sobre um território novo, sobre uma região que começa a ser explorada do ponto de vista da ciência empírica, por meio de pesquisa básica, utilizando-se da ampla indução sociológica com vistas a obtenção de validez transcultural do Direito (Cf. SOUTO, 1971, p. 21).

Essa tentativa teórica se impõe à Sociologia do Direito como tarefa fundamental, como condição de possibilidade a posteriori de todas as demais como ciência particular autônoma. Por isso, não foi desprovida de sentido aquela referência a Sócrates, pois o que se busca é uma formulação conceitual mais precisa sobre o Direito, para que a filodoxia possa se transmutar em Filosofia Jurídica e passar a trabalhar, a partir dos dados científicos fornecidos pela "Teoria Geral Científico-Empírica do Direito" (SOUTO, 1971, p. 24). Em seguida, veremos como se deu a formulação de uma Teoria Científico-Empírica da Justiça.

\section{V- Para uma Teoria Científico-Empírica da Justiça}

Para Souto, parece apriorístico afirmar que a justiça seja um ideal incessível à cognição humana (Cf. SOUTO, 1971, p. 83). O seu ponto de partida não é o conflito, multissecular, das filosofias sobre a ideia de justiça. Segue um outro caminho. Abandona a desconfiança na razão científica e enfrenta as dificuldades cognitivas que impediram muitos autores de desvendar o seu segredo. Souto sugere partir da "palavra grega $\delta l k \eta$, que significa justiça, deriva de Dik, Dic, no sentido de indicação, dictamen [...] de regra, norma" (SOUTO, 1971 , p. 83; 1974, p. 131; 1992, p. 42; 1997 a, p. 42), para afirmar que "as regras ou normas 
de conduta existem na sociedade, são fenômenos sociais" (SOUTO, 1971, p. 83). Nesse sentido, fazer uso do que a tradição oferece, equivale seguir o bom senso tradicional.

Portanto, se a justiça é algo relativo às normas de conduta, infere-se que regras e normas existem na sociedade e como tais são fenômenos sociais. Um estudo rigoroso e eficiente para se saber o que justiça significa precisa partir da observação científica do fenômeno na sociedade. Se a justiça diz respeito à intimidade de um fenômeno de normação social, como se pode afirmar de antemão que se trata de algo incognoscível? Dado que o normativo é um fenômeno social e que a justiça está nele presente, então, pode-se afirmar a possibilidade de sua apreensão pela ciência. Se se parte do pressuposto de que as normas de conduta implicam um dever ser e de que o valor é um fenômeno psíquico-social e cientificamente observável, logo não se pode negar a possibilidade do estudo científico dos valores que orientam o comportamento (Cf. SOUTO, 1971, p. 84)

Se as regras de condutas são fenômenos sociais, como estuda-las em sociedades primitivas, simples? Com base em dados etnológicos é possível identificar fenômenos normativos em sociedades mais simples, é possível identificar a presença da justiça no fenômeno de regulamentação social, mesmo que nele estejam imbricados, simultaneamente, elementos religiosos, morais e jurídicos. Porém, o que parece importar na investigação é detectar a presença de um sentido básico permanente do dever ser quer em sociedades simples quer em sociedades complexas, quer nas condutas dos etnólogos quer nas condutas das sociedades estudadas pela ciência etnológica (Cf. SOUTO e SOUTO, 1985, p. 237-240; SOUTO, 1992, p. 22-23).

Tudo indica que se há diferenças culturais, variações normativas no espaço e no tempo das sociedades humanas, elas são acidentais e cognitivas, as diferenças parecem consistir nos conhecimentos que informam o sentido básico permanente do dever ser. Destarte, pode-se dizer que os estudos etnológicos constatam a presença de algo invariável, o sentido básico permanente do dever ser, ao mesmo tempo que verificam a manifestação de algo variável e acidental, trata-se do aspecto cognitivo que varia no espaço e no tempo nas diversas culturas humanas.

Para Souto, em primeiro lugar, é possível identificar a presença de dois elementos no fenômeno normativo humano. Em segundo lugar, é possível distinguir esses dois 
elementos presentes no fenômeno normativo humano, em todas as sociedades em qualquer espaço-tempo. Em terceiro lugar, a identificação e a distinção dos dois elementos constitutivos do fenômeno normativo humano permite afirmar que um é permanente e o outro é variável (Cf. SOUTO, 1971, p. 85-86). Dessa maneira, em que medida as pesquisas sociojurídicas empíricas podem contribuir para as definições operacionais da justiça, da equidade, do direito e da moral (Cf. SOUTO, 1971, p. 87; 1974, p. 127; 1978, p. 76-77; 1992, p. 43) como fenômenos de dever ser que são?

Com a expressão sentido básico permanente do dever ser quer-se dizer sentimento do dever ser, e que esse sentimento do dever ser está presente, no ser humano, em qualquer espaço-tempo. Ademais, o sentido ou o sentimento e a volição ligam-se de modo necessário. A partir daí pode-se afirmar que se sente que algo deve ou não deve ser e se quer agir de acordo com esse sentimento ou de modo contrário a ele (SOUTO e SOUTO, 1997 b, p. 183). Esse é o mundo das regras éticas lato sensu. Contudo, como distinguir os fenômenos morais e jurídicos se em ambos está presente o sentido básico permanente do dever ser?

Essa distinção só é possível cientificamente por abstração, quando por abstração se separa o sentido básico permanente do dever ser ou sentimento do dever ser dos conhecimentos que o informam, dado que historicamente são indissociáveis. Se se distingue sentimento do dever ser dos conhecimentos que o informam, pode-se dizer que há a justiça propriamente dita e há a ideia de justiça. A justiça implica sentimento e a ideia de justiça se refere a conhecimento. Assim, justiça e ideia de justiça se definem por uma abstração científica do sentido ou sentimento do dever ser dos conhecimentos que o informam (Cf. SOUTO, 1971, p. 89; 1974, p. 130-131; 1978, p. 69-70; SOUTO e SOUTO, 1985, SOUTO, p. 240; 1992, SOUTO e SOUTO, p. 41-42; 1997 b, p. 190).

Em face do exposto, é possível afirmar que a justiça tem a dignidade da permanência como sentido básico permanente do dever ser, que é. Todavia, a ideia de justiça é essencialmente variável, contingente, relativa como o é o conhecimento humano. Tudo indica que as investigações socio-psicológicas revelam a sua formação e que a sutil diferença entre o sentimento e a ideia de justiça permite avançar nas definições do direito, da moral e da equidade. A partir da abstração a que a ciência confere licitude, entre sentimento e ideia de justiça, é possível definir o direito, a moral e a equidade. 
Os três fenômenos são constituídos de sentido básico permanente do dever ser ou sentimento de justiça ou justiça propriamente dita e de conhecimento ou ideia de justiça. Parece nítido que temos a união do normativo com o cognitivo ou a união do imperativo com o indicativo. Provavelmente, pode-se afirmar que o direito, a moral e a equidade são fenômenos normativos e de conhecimento. Neles estão presentes o sentimento de dever ser ou de justiça que lhes confere o caráter imperativo e a ideia de justiça que lhes atribui a natureza de conhecimento que são. Uma vez firmados substancialmente os fenômenos referidos, resta diferenciá-los (Cf. SOUTO, 1971, p. 90; 1974, p. 130-131; 1978, p. 68-69; 1992, p. 44; SOUTO e SOUTO, 1997 b, p. 184-191).

A atitude sociológica, para Souto, como atitude científica implica o máximo possível de descondicionamento ideológico durante a atividade produtora de conhecimento científico, ou seja, evitar ideias preconcebidas, descrever e explicar os fenômenos sociais significa ir além do meramente descritivo, importando para isso o rigor que envolve a explicação teórica (Cf. SOUTO, 1974, p. 162; 1978, p. 38; SOUTO e SOUTO, 1985, p. 38-43). Contudo, os cientistas sabem que partem de certos postulados que não podem ser testados empiricamente, ditos metacientíficos e que possibilitam e condicionam o fazer científico como: "o mundo existe", "podemos conhecer o mundo", "conhecemos o mundo mediante nossos órgãos dos sentidos", "os fenômenos são causalmente relacionados" (Cf. SOUTO, 1971, p. 94; SOUTO e SOUTO, 1985, SOUTO, p. 244; 1992, SOUTO e SOUTO, p. 45; 1997 b, p. 217). Diante do exposto, "se a ciência empírica ela própria descansa em postulados metacientíficos [...] por que não descansaria o direito [...]”? (SOUTO e SOUTO, 1997 b, p. 217).

Nesse sentido, pergunta-se, que há por trás do sentido básico permanente do dever ser?

Por trás do sentimento do que deve ser está, ao que parece, um postulado ético fundamental. Tal postulado seria o de que o mundo e o homem devem ser (existir) e desenvolver-se (ou ser cada vez mais profundamente). Ou seja, teríamos nesse postulado ético, de forma refinada e ideacional, tipicamente humana, o que, em última análise, parece nada mais ser senão o impulso de conservação individual e da espécie - que poderíamos chamar o impulso de ser - bem característico do mundo animal em geral. [...] ao que tudo indica, o impulso de ser, que parece constituir, afinal, a forma mais elementar de dever ser, como pauta fundamentalíssima de conduta animal que é (SOUTO, 1971, p. 95; 1974, p.136; 1978, p. 83-84; SOUTO e SOUTO, 1985, p. 243-244; SOUTO, 1992, p. 23 e 45; 1997 a, p. 43-45; SOUTO e SOUTO, 1997 b, p. 217). 
Interessa notar que o dever ser, em si mesmo, não se encontrará na natureza ideativa do homem, mas em sua natureza afetiva que, talvez, seja mais originária. Portanto, o dever ser encontra-se ligado ao sentimento do agradável (deve ser) e do desagradável (não deve ser), podendo-se afirmar que o sentimento do que deve ser é condicionado pelo impulso de ser, uma força ou pressão no sentido de ser (existir), como regra de conduta primária, como dever ser fundamental. Ademais, muito provavelmente, a origem imediata do dever ser é o sentido básico permanente ou o sentimento e a mediata e elementar o impulso de conservação do indivíduo e da espécie (Cf. SOUTO, 1971, p. 96). A seguir, veremos a importância da pesquisa empírica básica "O Sentimento e a Ideia de Justiça" para testar e comprovar as hipóteses da pesquisa teórica básica e fornecer os subsídios das definições operacionais da justiça, do direito, da moral e da equidade como condições a posteriori de possibilidade de uma Sociologia Jurídica Aplicada.

\section{VI - A definição do Direito a partir da sua "estrutura social"}

O direito representa um mínimo de preceitos de conduta considerados indispensáveis à convivência social. Para a tradição jurídica, o direito é considerado o mínimo ético, tradicionalmente significa o máximo de importância para o jurídico. Percebe-se como Souto faz uso da linguagem tradicional dos juristas, partindo dela para inovar substancialmente. Outrossim, se o direito deve construir a segurança nas relações sociais, deve apresentar o máximo possível de precisão e certeza em suas formulações (Cf. SOUTO, 1971, p. 100; 1974, p. 131-132; 1992, p. 44; SOUTO e SOUTO, 1997 b, p. 218). Contudo, precisão e certeza não apenas Lógico-Jurídicas, nem tampouco baseadas em axiomas metafísicos, indiscutíveis e necessários, da Filosofia do Direito, mas, fundamentalmente, nas formulações científicoempíricas atualmente insuperáveis da Ciência Social do Direito ou Sociologia Jurídica Básica.

Com efeito, como antes salientado, o que caracteriza os fenômenos de regulamentação social é a presença do sentido básico permanente do dever ser ou sentimento de justiça e o que os distingue é o conhecimento que os informa. Por isso, a pesquisa empírica exploratória básica "O Sentimento e a Ideia de Justiça” procurou lastrear os Fundamentos da Sociologia Jurídica assumindo como tarefa fundamental determinar qualitativamente ou substantivamente o conteúdo de algo que pudesse ser chamado direito vivo ou simplesmente 
direito. Pela primeira vez essa tarefa qualitativa foi tentada por meio de pesquisa empírica. Essa pesquisa foi realizada na Alemanha em 1965. Tentou-se a formulação de uma Teoria da Justiça baseada em pesquisa empírica (Cf. SOUTO, 1971, p. 102-103; 1974, p. 129; 1978, p. 74-75; SOUTO e SOUTO, 1985, p. 240; 1992, p. 43; SOUTO e SOUTO, 1997 b, p. 293).

Tratou-se de uma pesquisa exploratória básica que estudou o sentimento e a ideia de justiça entre os estudantes estrangeiros na Universidade de Colônia em 1965 com período de permanência de não mais de um ano, foram obtidos um total de 175 questionários aplicados a estudantes de 42 nacionalidades, mas 148 foram aproveitados para análise e tentou três novas perspectivas: 1) baseou-se na distinção, por abstração, de sentimento e ideia de justiça; 2) investigou estudantes de diferentes nacionalidades sob a suposição de que o problema da justiça é um problema do homem; 3) se conduziu com referência a uma teoria da justiça, fundando-se no seguinte quadro hipotético: existência, permanência e variabilidade de um sentimento do dever ser, associação necessária desse sentimento com uma ideia que pode estar: a) de acordo com a ciência; b) de acordo com a metaciência; c) de acordo com o conhecimento das circunstâncias particulares de um caso; d) pode ser outra ideia (Cf. SOUTO, 1971, p. 103-105; 1974, p. 129; 1978, p. 76-77; SOUTO e SOUTO, 1985, p. 240; 1997 b, p. 296, 319-320).

A abstração do sentimento e ideia de justiça tornou possível a investigação e forneceu elementos empíricos para a formação de quatro definições operacionais importantes: justiça, direito, moral e equidade. A partir da pesquisa realizada, passou-se a chamar justiça o simples sentimento do dever ser experimentado por todos os respondentes. Respectivamente: 1) direito a associação do sentimento de justiça com uma ideia de acordo com a ciência; 2) moral a associação do sentimento de justiça com uma ideia de acordo com a metaciência; 3) equidade a associação do sentimento de justiça com uma ideia de acordo com o conhecimento das circunstâncias particulares de um caso (Cf. SOUTO, 1971, p. 105; 1974, p. $129 ; 1978$, p. $80 ; 1992$, p. 33-34; SOUTO e SOUTO, 1985, p. 240; 1997 b, p. 319-320). Pareceu aos pesquisadores não haver dúvida razoável de que o padrão aceito pela maioria dos estudantes estrangeiros pesquisados na Universidade de Colônia (conformidade com o sentimento de justiça e com a ciência) é direito vivo, no sentido de norma socialmente aceita.

\section{VII - Direito e Formas de Coercibilidade}


Verificou-se, através da pesquisa exploratória básica "O Sentimento e a Ideia de Justiça”, que há uma estrutura social do Direito que se compõe de, pelo menos, dois elementos: o sentimento de justiça informado por dados da ciência empírica atual seja qual for a área científica. Por um lado, o sentimento de justiça é o elemento imperativo da fórmula do Direito, é o dever ser que deve ser apreendido na realidade social total como conhecimento que é. Por outro lado, a ideia de justiça é o elemento indicativo ou cognitivo da fórmula do Direito. Eis os dois elementos constitutivos do Direito como fato social (Cf. SOUTO, 1971, p. 106; 1974, p. 130-131; 1978, p. 68; SOUTO e SOUTO, 1985, p. 241; 1997 b, p. 214).

Se a comunidade dos homens de ciência estabelece os critérios gerais e atuais do que é considerado ciência válida universalmente, o mesmo ocorre com o Direito e com o seu critério de juridicidade. Identifica-se como Direito o sentimento de justiça unido aos dados da ciência empírica atual, este é o padrão de juridicidade, é o critério geral e atual do Direito considerado universal ou transculturalmente válido (Cf. SOUTO, 1971, p. 112 e 117; 1978, p. 66-69; SOUTO e SOUTO, 1997 b, p. 215-217). Dado que o direito é apreendido na realidade social total por métodos e técnicas de pesquisa empírica, pode-se falar de um direito social ou de um direito vivo, uma clara referência ao Sociólogo do Direito Eugen Ehrlich (Cf. 1986, p. 378; SOUTO, 1978, p. 61), como norma de conduta socialmente válida e aceita.

Há que distinguir-se as normas em jurídicas e morais. O critério, como visto acima, é o conhecimento que informa o sentimento do dever ser. Por um lado, o Direito é o que está de acordo com o sentimento do dever ser e com a ciência atual. Por outro lado, a moral é o que está de acordo com o sentimento do dever ser e com o conhecimento metacientífico, próprio de uma comunidade moral específica. Direito e moral são normas obrigatórias, contudo, a extensão da obrigatoriedade depende do tipo de conhecimento que informa esses fenômenos normativos. A obrigatoriedade do Direito se refere ao social em sua totalidade, diferente do que ocorre com a obrigatoriedade social parcial da moral que só atinge os membros da comunidade moral específica, a exemplo de judeus, cristãos, mulçumanos, budistas, etc. (SOUTO, 1971, p. 109-110).

Quanto à relação entre Direito e formas de coercibilidade, Souto afirma que a força física é um elemento exterior ao jurídico. Para o Direito apreendido científica-empiricamente, como estrutura social, a força lhe é um elemento acidental e determinado, mas não essencial 
como visto acima. Portanto, se se chama Direito o sentimento de justiça de acordo com dados insuperáveis da ciência atual, percebe-se que a força física não faz parte da composição social do jurídico. Nesse sentido, há Direito independentemente da força física, o Direito é anterior aos modos de expressão formais institucionalizados ou formalizados. O Direito existe fora das formas de coercibilidade como a lei, o costume, os regulamentos, os contratos, a decisão judicial (Cf. SOUTO, 1971, p. 121-126; SOUTO e SOUTO, 1997 b, p. 211). Reconhece também, senão vejamos:

\begin{abstract}
A destacada importância, para as sociedades complexas organizadas em Estado, das formas de coercibilidade estatal, nessas sociedades tendendo as regras em consonância com o sentimento de justiça e com dados de ciência - as regras de direito da sua terminologia - a ser conteúdo dessas formas para ganhar maior força de atuação social ou maior positivação (SOUTO e SOUTO, 1997 b, p. 211 - Grifos no original).
\end{abstract}

Para os autores, Direito, em sentido próprio, é constituído pelo sentimento de justiça e impulso de conservação do indivíduo e da espécie como seu elemento infraestrutural informado por dados da ciência empírica atual. Esse conteúdo poderá assumir formas institucionalizadas de coercibilidade. Dessa forma, poderá contar com a força física para maior eficácia e eficiência do seu conteúdo. Todavia, a obrigatoriedade e a força do direito se fundam no seu conteúdo ético-científico-empírico e esse determina a própria natureza jurídica da força física. Por isso mesmo, tradicionalmente, encontra-se o equívoco de atribuir ao Direito uma essência coercitiva, ademais, o problema da explicação da obediência ao Direito sem a necessidade de coação (Cf. SOUTO, 1971, p. 122-124).

Verifica-se que Souto reformula, também, a teoria das fontes do direito. No entanto, mantém as metáforas tradicionalmente usadas pelos juristas, atribuindo à palavra fonte os significados de princípio, fundamento ou origem. Contudo, utiliza a linguagem tradicional para mostrar o seu paradoxo. Se fonte indica princípio, fundamento ou origem parece indicar um sentido acentuadamente substancial, muito embora os lógicos das técnicas coercíveis do direito ou teóricos da dogmática jurídica estabeleçam as fontes formais como as típicas manifestações estatais do direito, fontes autorizadas e fixadas em textos normativos. Como afirma Souto,

Sendo evidentemente fundamentais aquelas que são consubstanciadas por lei, jurisprudência e costume. [...]. As chamadas 'fontes formais', que seriam diversas formas de manifestação necessária do direito, pois seu conteúdo pode não ser jurídico; de outro lado, pode haver direito manifestando-se sem ser através dessas 'fontes formais', por exemplo, mediante a simples palavra, escrita ou oral. [...]. E 
por que, se aceitássemos a expressão 'fontes formais do direito', a simples palavra não seria uma dessas 'fontes formais', se elas se definem como as diversas formas de manifestação do direito na vida social, e a mera palavra é uma dessas formas, embora não seja dotada de coercibilidade? Por tudo isso preferimos usar, ao invés da expressão 'fontes formais do direito', a denominação 'formas de coercibilidade', que exclui, de seu natural, a manifestação do jurídico através de meios não coercíveis. Em suma, haveria uma só fonte (princípio, fundamento, origem) do direito, e êste se manifesta quer mediante formas de coercibilidade, quer através de formas não coercíveis, como a simples palavra escrita ou oral (1971, p. 129-130 - Grifos no original).

Observa-se que Souto, a partir da pesquisa exploratória básica sobre "O Sentimento e a Ideia de Justiça", testa e comprova sua hipótese teórica de que o Direito é a junção de conhecimento científico atual ao sentimento de justiça, ou seja, é "o ético-científico atualmente incontestável" (SOUTO, 1971, p. 128). Há uma única fonte do Direito, "o sentimento individual básico do dever ser a se informar de conhecimento acorde com o estado atual da ciência - sentimento êsse a se socializar e objetivar por uma informação cognitiva" (SOUTO, 1971, p. 126). Todavia, como o dado de conhecimento sempre informa os conteúdos normativos de formas de coercibilidade, nem sempre o conteúdo dessas formas de coercibilidade está de acordo com conhecimento científico atualmente insuperável. O que é considerado "direito" pode expressar o "torto".

Tudo indica que embora haja uma formulação científico-empírica-social do Direito, a conceituação assegura o não afastamento que o uso linguístico faz com a palavra direito. Para isso, Souto faz uso da lição de Lévy-Bruhl, senão vejamos:

A palavra 'direito', em francês, droit (como em inglês, right, em alemão, recht, em italiano, diritto, etc.), liga-se a uma metáfora na qual uma figura geométrica assumiu um sentido moral e depois jurídico: o direito é a linha reta, que se opõe à curva, ou à oblíqua, e aparenta-se às noções de retidão, de franqueza, de lealdade nas relações humanas (1988, p. 3 - Grifos no original).

Note-se que precisão e segurança, o que se espera do Direito como mínimo pacificador social, encontra-se fundamentalmente, para Souto, na sua composição social: síntese de sentimento de justiça e razão científica (Cf. SOUTO, 1978, p. 94). Como dito acima, a única fonte do Direito, a junção de conhecimento científico atual ao sentimento de justiça pode ser conteúdo das formas de coercibilidade como a lei, o costume, a decisão judicial. Para Souto, a juridicidade da lei, do costume e da decisão judicial encontra-se na consonância com o critério científico-empírico do Direito. Consequentemente, o Direito como formulado por Souto pode ser conteúdo da lei, do costume, da decisão judicial e das demais formas de coercibilidade (Cf. SOUTO, 1971, p. 126-135). 
Ademais, da junção de conhecimento científico atual ao sentimento de justiça resulta, de modo simplificado, que não há Direitos a comparar porque o Direito é um só (Cf. SOUTO, 1971, p. 150-159); não se ampara a distinção tradicional entre direito positivo e direito natural porque só há um Direito. E todo Direito é, a um só tempo, positivo e tão somente observável a partir da natureza ético-científica do homem (Cf. SOUTO, 1971, p. 165-167); não se mantém a distinção secular entre direito público e direito privado porque a presença do Estado é um dos pilares de sustentação da distinção e o Direito como sentimento de justiça informado por dados insuperáveis da ciência atual é anterior às formas de coercibilidade e não possui vínculo necessário com a força física, apenas acidental (Cf. SOUTO, 1971, p. 167-169).

\section{Conclusão}

Este artigo procurou salientar a originalidade do pensamento sociojurídico de um autor brasileiro e homenageá-lo nos seus 90 anos. Como visto ao longo do texto, tentou-se fazer uma análise o mais possível descritiva do pensamento do primeiro sociólogo do direito estudado pelo autor deste trabalho, ainda na graduação em Direito, em Pesquisa de Iniciação Científica, na Universidade Estadual da Paraíba.

Ademais, procurou mostrar a atualidade do livro Introdução ao Direito como Ciência Social meio século depois e, ainda, a sua localização na trajetória acadêmica de Cláudio Souto. Evidenciou-se que o livro Introdução ao Direito como Ciência Social é um divisor na trajetória acadêmica de Souto. Mostrou-se a que tradição sociológica Souto se alinha e, em que medida, o autor deu continuidade, de modo original, ao procurar determinar qualitativamente ou substantivamente o conteúdo de algo que pode ser chamado direito vivo ou simplesmente direito.

Os resultados preliminares dessa investigação, centrada em um único livro, revelaram uma reconstrução da teoria jurídica ao determinar através de pesquisa exploratória básica, as definições operacionais de justiça, direito, moral e equidade. Esse trabalho tornou possível a conexão entre uma Teoria Sociológica Geral do Direito e uma Sociologia do Direito Aplicada. Portanto, o que o autor denominou de nova Teoria Geral do Direito implicou uma reformulação das relações entre o que designou de saberes jurídicos fundamentais como se viu ao longo do texto: Lógica Jurídica ou Dogmática Jurídica, Sociologia do Direito e Filosofia Jurídica. Essa atitude implicou na formulação de uma Teoria 
Geral Científico-Empírica do Direito com repercussões nos temas clássicos que compõem a Teoria Geral do Direito.

Resta dizer que o livro, objeto deste artigo, foi comentado pelo autor deste texto quando, por iniciativa da Associação Brasileira de Sociologia do Direito ${ }^{1}$ e do Moinho Jurídico/UFPE ${ }^{2}$, comemorou-se os 90 anos do professor Cláudio Souto.

\section{Referências}

EHRLICH, Eugen. Fundamentos da Sociologia do Direito. Brasília: UnB, 1986.

LÉVY-BRUHL, Henri. Sociologia do Direito. São Paulo: Martins Fontes, 1988.

MARCONDES, Danilo. Iniciação à História da Filosofia: Dos Pré-socráticos a Wittgenstein. Rio de Janeiro: Jorge Zahar Editor, 2008.

SOUTO, Cláudio. Da Inexistência Científico-Conceitual do Direito Comparado: conceituação do indagar comparativo mais específico da Ciência do Direito. Recife, 1956.

SOUTO, Cláudio. Da Irrealidade Jurídico-Definitiva do Direito Natural: nova visualização do fenômeno jusnaturalista. vol. I, Recife: Imprensa Universitária, 1958.

SOUTO, Cláudio. Da Irrealidade Jurídico-Definitiva do Direito Natural: nova visualização do fenômeno jusnaturalista. vol. II, Recife: Imprensa Universitária, 1960.

SOUTO, Cláudio. As Imunidades Parlamentares. Recife: Imprensa Universitária, 1962.

SOUTO, Cláudio. Introdução Crítica ao Direito Internacional Privado. Recife: Imprensa Universitária, 1964.

SOUTO, Cláudio. Fundamentos da Sociologia Jurídica. Recife: Imprensa Universitária, 1968.

SOUTO, Cláudio. Introdução ao Direito como Ciência Social. Rio de Janeiro: Tempo Brasileiro, 1971.

SOUTO, Cláudio. Teoria Sociológica Geral. Porto Alegre: Editora Globo, 1974.

SOUTO, Cláudio. Teoria Sociológica do Direito e Prática Forense. Porto Alegre: Sérgio Antonio Fabris Editor, 1978.

SOUTO, Cláudio. O que é pensar sociologicamente. São Paulo: EPU, 1987.

SOUTO, Cláudio. Ciência e Ética no Direito: uma alternativa de Modernidade. Porto Alegre: Sérgio Antonio Fabris Editor, 1992.

SOUTO, Cláudio. Tempo do Direito Alternativo: Uma Fundamentação Substantiva. Porto Alegre: Livraria dos Advogados Editora, 1997a.

\footnotetext{
${ }^{1}$ Disponível em: < https://www.abrasd.com.br/premio-teses-claudio-souto $>$. Acesso em 16 de abril de 2021.

${ }^{2}$ Disponível em: $\langle$ https://www.youtube.com/watch?v=f0PmcPccLCQ\&t=11s $\rangle$. Acesso em 16 de abril de 2021.
} 
SOUTO, Cláudio e SOUTO, Solange. A Explicação Sociológica: uma introdução a Sociologia. São Paulo: EPU, 1985.

SOUTO, Cláudio e SOUTO, Solange. Sociologia do Direito: Uma Visão Substantiva. Porto Alegre: Sérgio Antonio Fabris Editor, 1997 b. 